\title{
Rapid Penetration of Potassium and Other Salts into the Frog Tongue Papilla
}

\author{
Haruhide HAYASHI \\ Department of Physiology, School of Dentistry, Tokyo Medical \\ and Dental University, Bunkyo-ku, Tokyo, 113 Japan
}

\begin{abstract}
The permeabilities of the frog tongue epithelium for potassium and other ions during a short time span were investigated electrophysiologically. The fungiform papilla of the bullfrog tongue was suctioned into a U-shaped glass suction electrode, through which Ringer solution was circulated. Compound nerve action potentials were recorded antidromically from the electrode following electrical stimulation of the glossopharyngeal nerve. When more than 5-10 mM potassium salts, $30 \mathrm{~mm} \mathrm{RbCl}, 30 \mathrm{~mm} \mathrm{CsCl}, 0.025 \mathrm{~g}$ in dl solution tetrodotoxin, $0.1 \mathrm{~g}$ in $\mathrm{dl}$ solution lidocaine hydrochloride or $3 \mathrm{~g}$ in dl solution ethanol, each of which was dissolved in Ringer solution containing $1.9 \mathrm{mM} \mathrm{KCl}$, were flowed through the suction electrode, only the negative components of action potentials were gradually reduced and finally disappeared. The time needed for $50 \%$ reduction of negative components was about $10 \mathrm{sec}$ for $0.1 \mathrm{M}$ potassium salts and longer for the nonelectrolytes. A single suctioned papilla, which was flowed with various test solutions, was stimulated electrically and the change in current threshold of the papillary nerve was measured by recording orthodromic action potentials from the glossopharyngeal nerve. The threshold decreased within $10 \mathrm{sec}$ after 0.05 $\mathrm{M} \mathrm{BaCl}_{2}$ was flowed, but increased within $10 \mathrm{sec}$ after $0.1 \mathrm{M} \mathrm{KCl}$ was flowed. The reduction of negative components of nerve action potentials may be due to the conduction block induced by potassium and other ions invading to the space around axon terminals. The threshold change also may be induced by the ions reaching the axon. These results suggest that chemical substances can rapidly penetrate the tongue epithelium of the frog, reach the papillary nerve fibers and contribute or modify gustatory informations.
\end{abstract}

The tongue surface of the mammal is covered with the stratum corneum and is not easily penetrated with chemicals as formerly suggested by BEIDLER (1965).

Received for publication September 5, 1977

Present address: Neurobiology and Anesthesiology Branch, National Institute of Dental Research, National Institutes of Health, Bethesda, Maryland 20014, U.S.A.

林 治秀 
Only a few chemicals, for example, high concentrations of alcohol have been found to penetrate the tongue epithelium of the cat and to stimulate the trigeminal portion of the lingual nerve with a long latency (Hellekant, 1965). Mistretta (1971) showed that the keratinized layer of stripped tongue epithelium of the rat was as effective a barrier to chemical penetration as abdominal skin. However, it has been suggested that some chemicals could easily invade into the frog tongue through the mucous membrane layer, since this layer is lacking the stratum corneum (Taglietti and Casella, 1971). OzeKi and Noma (1972) reported that, after the frog tongue had been soaked in tetrodotoxin for a short period, the gustatory responses in primary taste neurons were suppressed, whereas the depolarizing responses of taste cells produced by chemical stimuli were not reduced in magnitude (OzeKI and Noma, 1972; AKAIKe and SATO, 1975). Both studies suggest that the penetration of chemicals into the frog tongue occurs to some extent.

It is well-known that some chemicals, for example, potassium ions or local anesthetics change the nerve excitability and easily block the conduction of action potentials (Hodgkin, 1947, 1951; SATo and FukUda, 1953; Hashimura and WRIGHT, 1958; SHANES et al., 1959). Therefore, the present experiments were performed to investigate electrophysiologically the permeabilities of the frog tongue epithelium, from the changes in the shape of action potentials and in the threshold for electrical stimulation of a single papilla, which reflect the excitability change of the nerves running beneath the mucous membrane, upon application of salts or other chemicals on the epithelium. The results demonstrated that potassium ions and some other chemicals can easily penetrate the mucous membrane of the frog tongue and can rapidly reach the nerve fibers in the papillae.

The study has already been communicated briefly (HAYASHI, 1976).

\section{METHODS}

Bullfrogs, Rana catesbeiana, were used in all experiments. The animal was anesthesized with an intraperitoneal injection of a $50 \mathrm{~g}$ in dl solution of urethane Ringer-solution $(5 \mathrm{ml} / \mathrm{kg})$. The experimental set up is shown in Fig. 1. The glossopharyngeal nerve was isolated and lifted onto a pair of platinum wire electrodes of $120 \mu \mathrm{m}$ diameter (d) for electrical stimulation or recording. A fungiform papilla was suctioned into a U-shaped suction electrode, made of glass capillary tube of $1 \mathrm{~mm}$ diameter, both ends of which were connected with polyethylene tubes ( $1 \mathrm{~mm}$ diameter). This electrode was used for recording antidromic nerve action potentials and for electrical or chemical stimulation to a single papilla. An indifferent electrode was placed on the body surface.

Frog Ringer solution, composed of $111.2 \mathrm{~mm} \mathrm{NaCl}, 1.9 \mathrm{~mm} \mathrm{KCl}, 1.1 \mathrm{~mm}$ $\mathrm{CaCl}_{2}, 2.4 \mathrm{~mm} \mathrm{NaHCO}$ and $0.06 \mathrm{~mm} \mathrm{NaH} \mathrm{PO}_{4}$, was stocked in a polyethylene syringe (a), flowed constantly through the suction electrode and was withdrawn 


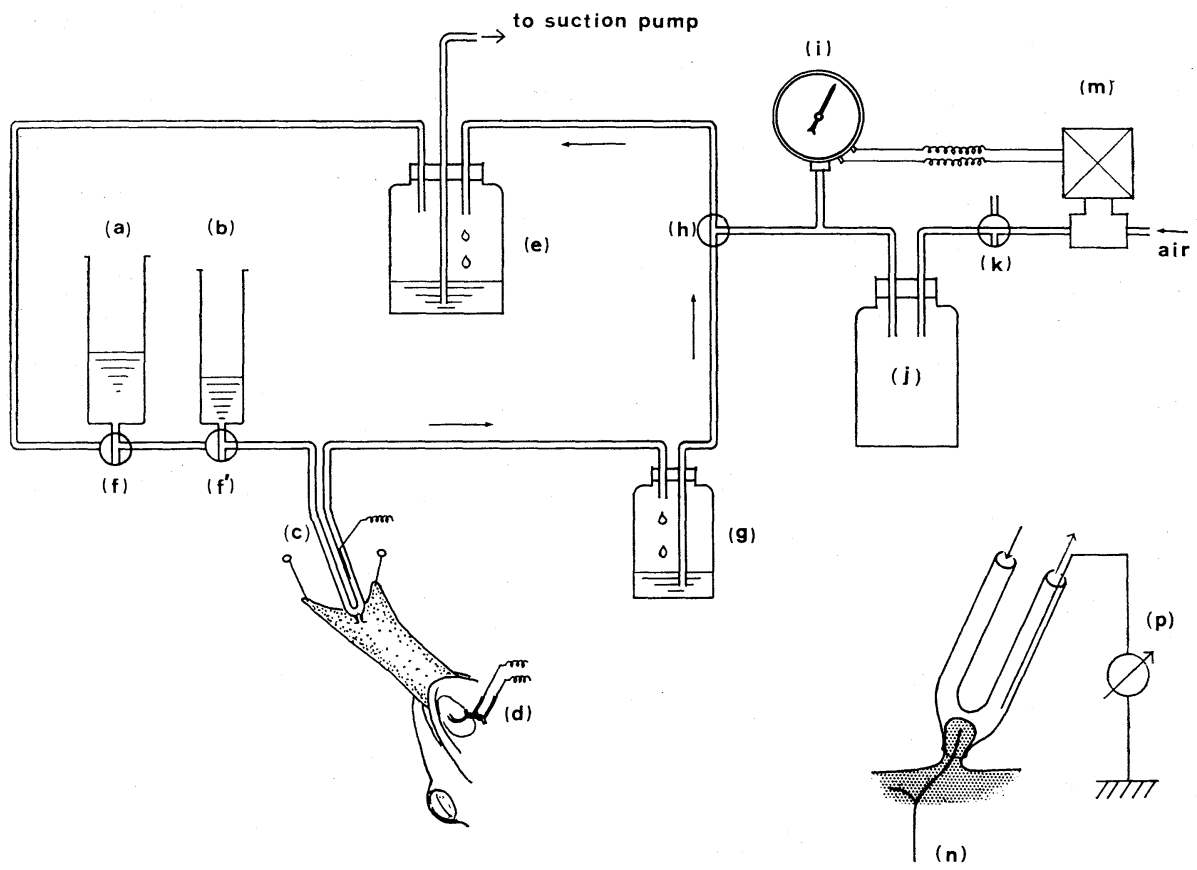

Fig. 1. Drawing showing the experimental set up. (a) and (b): polyethylene syringes, in which Ringer and test solutions were stored respectively. (d) glossopharyngeal nerve lifted on the silver wire electrodes for electrical stimulation and recording. (e). (g) and (j): glass bottles. (f), ( $\left.f^{\prime}\right),(h)$ and $(k)$ : three-way stopcocks. (i): pressure meter with present electrical contacts. (m): electromagnetic valve. (n): glossopharyngeal nerve dissected. (p): preamplifier. In the normal state, Ringer solution flowing through a suction electrode (c) is dropping into a bottle (g), the negative pressure of which is kept at the same level with a pressure meter (i) and a valve (m). When a stopcock ( $\left.\mathrm{f}^{\prime}\right)$ is switched, a test solution in a syringe (b) begins to flow in exchange for Ringer solution. Inset of lower right side of this figure represents the enlargement of the suction electrode (c). Electrical activities of the glossopharyngeal nerve (n) were recorded with a preamplifier (p) without noise, while solutions flow through this electrode.

into a glass bottle (g). When an inserted three-way stopcock $\left(f^{\prime}\right)$ was switched, the Ringer flow was stopped and a test solution in a syringe (b) began to flow simultaneously. Glass bottles $(e, g, j)$ prevented a sudden change of pressure and electrically isolated the suction electrode from ground. The negative pressure of the bottle ( $\mathrm{g}$ ) was always maintained at $47 \mathrm{~mm} \mathrm{Hg}$ by both a pressure meter with preset electrical contacts (i) and a electromagnetic valve (m) in order to keep the solution flow rate in the suction electrode constant.

In order to know approximate rising and falling time of concentration at the small orifice of the suction electrode, transient time courses of impedance changes were measured when the stopcock $\left(\mathrm{f}^{\prime}\right)$ was turned on and off. AC current of 
$1,000 \mathrm{~Hz}$ was continuously let flow between a silver wire inside electrode and the ground through a papilla or another silver wire put at the orifice of the electrode instead of pappilla, both of which were the same in result. The amount of current was detected as voltage between both terminals of a resistor inserted in series and was written with a pen recorder after rectified and smoothed. The period, during which the stopcock ( $\left.f^{\prime}\right)$ was kept on, was detected with a microswitch set on its lever and is shown as a upward deflection in the lowest trace in Fig. 2 or as a break of a vertical broad band on the left side traces in Fig. 3. Figure 2 shows time courses of concentration change obtained, when deionized water was exchanged for test solutions of $0.01,0.1,1 \mathrm{M} \mathrm{NaCl}$. The time needed for reaching the maximum concentration of each solution from switching the stopcock was almost same and about $2.6 \mathrm{sec}$, and the test solutions were completely exchanged for deionized water within $10 \mathrm{sec}$ after switching back.

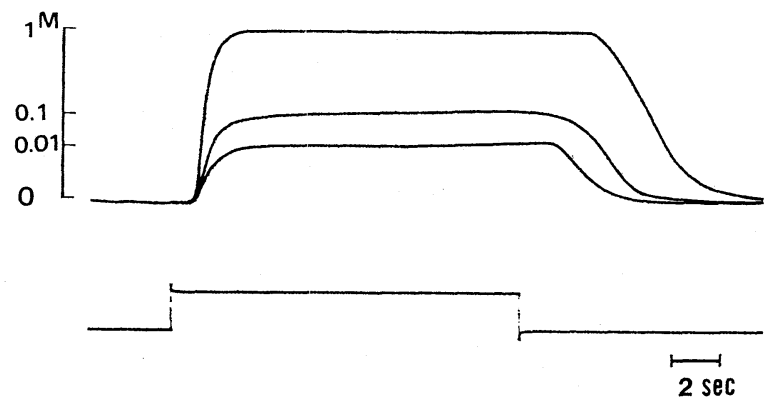

Fig. 2. The time courses of concentration change of $0.01,0.1$ and $1 \mathrm{M} \mathrm{NaCl}$ solutions. The upward deflection in the lowest trace indicates the period during which the stopcock was switched to $\mathrm{NaCl}$ solution from deionized water.

Responses recorded from papillary nerves and from the glossopharyngeal nerve were fed to a preamplifier (Iwasaki HP-601) and displayed on an oscilloscope (Nihon Kohden VC-7). The data obtained were stored on magnetic tape with a data recorder (TEAC R-260) and were later photographed with a kymograph camera (Nihon Kohden).

The temperature of both test and Ringer solution was kept at a room temperature of $20-23^{\circ} \mathrm{C}$.

\section{Experimental procedure}

(a) Electrical stimulation to the glossopharyngeal nerve. The glossopharyngeal nerve was stimulated with pulse waves $(0.1 \mathrm{msec}$ duration, $1 \mathrm{~Hz})$ generated with an electronic stimulator (Nihon Kohden MSE-40). Antidromic nerve action potentials were recorded from the suctioned papilla which was circulated constantly with Ringer or test solution.

(b) Chemical stimulation to a papilla. In a few experiments a suctioned 
papilla was stimulated with $0.5 \mathrm{M} \mathrm{NaCl}$ solution. Impulses originating in the papilla were conducted antidromically along a fiber branch into the other neurally connected papillae. Antidromic impulses were recorded from one of such adjacent papillae which was suctioned by another U-shaped suction electrode, through which test and Ringer solutions were flowed.

All the ionic chemicals, which were tested in procedure (a) and (b) and are listed in Table 1, were dissolved both in Ringer solution and deionized water, and non-ionic chemicals were dissolved in only Ringer solution.

(c) Electrical stimulation to a papilla. A suctioned papilla was stimulated electrically with pulse waves $(0.1 \mathrm{msec}$ duration, $1 \mathrm{~Hz})$ and conducted nerve action potentials were recorded from the glossopharyngeal nerve. The threshold current needed for excitation of papillary nerve was measured for $60 \mathrm{sec}$ following introduction of $0.1 \mathrm{M} \mathrm{KCl}, 0.1 \mathrm{LiCl}, 0.05 \mathrm{M} \mathrm{BaCl}_{2}$ in deionized water or a control Ringer solution through the electrode.

\section{RESULTS}

\section{Reduction of negative components of antidromic nerve action potentials}

Compound action potentials elicited by electrical stimulation at one per second to the glossopharyngeal nerve were recorded antidromically from a suctioned papilla with the procedure (a) in the methods section. Although the shape of these action potentials were in many cases polyphasic with the first positive phase regarding to the recording electrode, only the diphasic potentials with positive-negative voltage sequence were selected and shown in figures to make interpretation easy. Figure 3 shows sequentially the effect of $0.1 \mathrm{M}$ potassium benzoate, which has inhibitory action on gustatory responses in the rat (BEIDLER, 1961; Miller, 1971), on the action potentials. In this figure the period of application of potassium benzoate is indicated by a thin vertical line with denotation of K-benzoate. The amplitude of the negative component reduced gradually and disappeared finally $10 \mathrm{sec}$ later, leaving the positive component as it was. After application of potassium benzoate for $30 \mathrm{sec}$, it was replaced by Ringer solution. The negative component subsequently reappeared, increased gradually, and recovered entirely in about $100 \mathrm{sec}$.

The negative components of single unit spikes, which were elicited in an adjacent papilla with chemical stimulation $(0.5 \mathrm{M} \mathrm{NaCl})$ and conducted antidromically to the recorded papilla, were also reduced by application of potassium benzoate to recorded papilla. In Fig. 4 (a), a diphasic single unit spike obtained with the procedure (b) is shown. It is similar to that observed by TAGLIETTI et al. (1969). When the recorded papilla was exposed to $0.1 \mathrm{M}$ potassium benzoate, amplitude of the negative component decreased gradually (b) and changed finally to a almost monophasic spike (c) $10 \mathrm{sec}$ after onset. No significant difference was observed among the changes in shapes induced by $0.01,0.1$ and $1 \mathrm{M}$ solutions, or deionized 

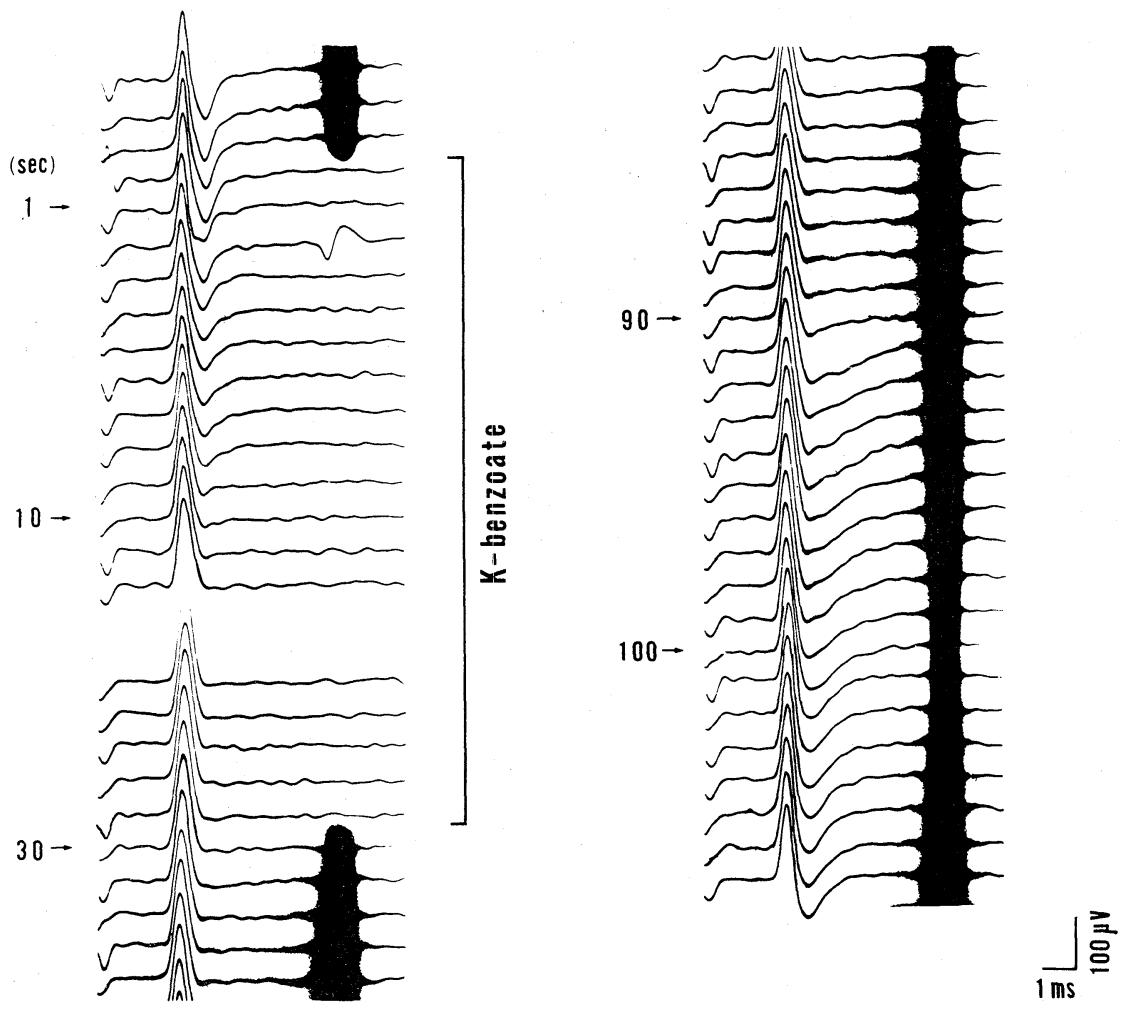

Fig. 3. The compound nerve action potentials recorded antidromically from a suctioned papilla. The glossopharyngeal nerve was stimulated electrically once per second and the potentials obtained were arranged from up to down. Upward deflection is positive regarding to the recording electrode. Vertical broad bands along the right side of the potentials indicate application of Ringer solution through the electrode, and the break of the band, which corresponds to the upward deflection of the lowest trace in Fig. 2, represents the period during which $0.1 \mathrm{M}$ potassium benzoate was applied substituted for Ringer solution. This period is also indicated by a vertical thin line with denotation "K-benzoate."

(a)

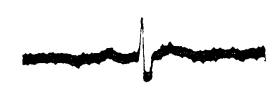

(b)

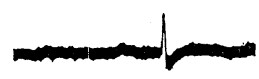

(c)

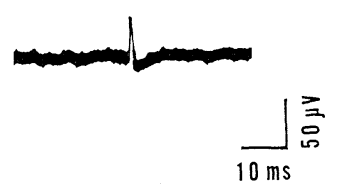

Fig. 4. Single unit spikes recorded antidromically from a papilla. They were elicited by chemical stimulation $(0.5 \mathrm{M} \mathrm{NaCl})$ applied to another papilla and conducted to the recorded papilla. (a): normal diphasic spike. (b): the spike of the same unit recorded $6 \mathrm{sec}$ after $0.1 \mathrm{M}$ potassium benzoate was applied to the recorded papilla. (c): $10 \mathrm{sec}$ after the onset of the application. 
(a)

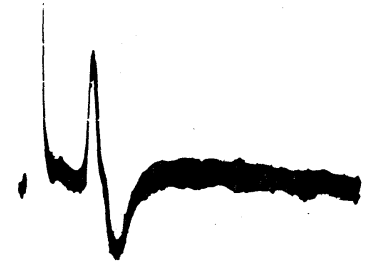

(C)

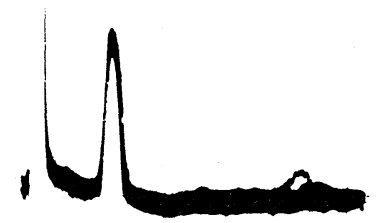

(b)

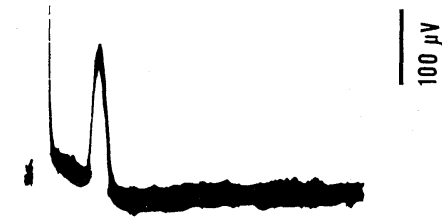

(d)

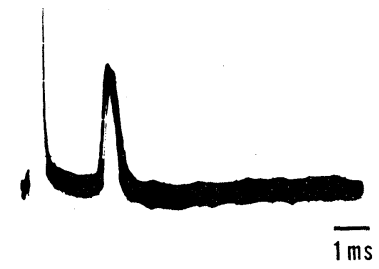

Fig. 5. Antidromic nerve action potentials recorded from a papilla elicited by electrical stimulation to the glossopharyngeal nerve. Eight traces were superimposed. (a): normal action potentials. (b): the action potentials lacking negative components induced by application of $0.1 \mathrm{M} \mathrm{KCl}$ to the recording papilla. (c): similar shaped action potentials recorded from the papilla, just the top of which was suctioned into the recording electrode. (d): similar shaped action potentials recorded from the other papilla, the head of which was crushed beforehand.

water and Ringer solutions.

Although it is not clear that which part of potential changes was recorded and formed the shape of action potentials shown in Figs. 3 and 4, the recording from a suction electrode could be basically regarded as an analogy of extracellular recording of action potentials in nerve fibers (BINLEY, 1974). On the basis of this concepture, the observed abolition of the negative components, which would correspond to the change from diphasic to monophasic recording in nerve fibers must indicate that the antidromic nerve action potentials were blocked and could not conduct to the axon terminals of the papillary nerves. Such monophasic action potentials, which are also shown in Fig. 5 (b), resembled those obtained by intentionally blocking the conduction of impulses to the axon terminals. This occurred when just the head portion of the papilla was suctioned into the electrode (Fig. 5 (c)), or when the papillary head was pinched beforehand or crushed with a fine forceps (Fig. 5 (d)).

\section{Effective and ineffective chemicals}

It has been concluded that conductions of antidromic action potentials were blocked at the axon terminals of papillary nerves by potassium benzoate which is consist of potassium cations and benzoate anions. The former can cause conduction block on nerve fibers and the latter has inhibitory effects on gustatory responses (BEIDLER, 1961; MILLER, 1971). To determine which one of both has 
Table 1. Effective and ineffective chemicals. Salts were dissolved in both Ringer solution and deionized water, but nonelectrolytes only in Ringer. Concentration without denotation was $0.1 \mathrm{M}$.

\begin{tabular}{|c|c|}
\hline Effective & Ineffective \\
\hline $0.1 \mathrm{M} \mathrm{KCl}$ & $0.1 \mathrm{M} \mathrm{NaCl}, \mathrm{LiCl}$ \\
\hline $\mathrm{RbCl}, \mathrm{CsCl}$ & $\mathrm{CaCl}_{2}, \mathrm{BaCl}_{2}, \mathrm{MgCl}_{2}$ \\
\hline $\mathrm{KI}$ & $\mathrm{SrCl}_{2}, \mathrm{HgCl}_{2}$ \\
\hline $\mathrm{KNO}_{2}$ & $\mathrm{NaNO}_{2}$ \\
\hline $\mathrm{KNO}_{3}$ & $\mathrm{NaNO}_{3}, \mathrm{Sr}\left(\mathrm{NO}_{3}\right)_{2}$ \\
\hline $\mathrm{CH}_{3} \mathrm{COOK}$ & $\mathrm{CH}_{3} \mathrm{COONa}$ \\
\hline potassium citrate & sodium citrate \\
\hline potassium benzoate & sodium benzoate \\
\hline $\mathrm{KH}_{2} \mathrm{PO}_{4}$ & $\mathrm{NaH}_{2} \mathrm{PO}_{4}$ \\
\hline $\mathrm{K}_{2} \mathrm{HPO}_{4}$ & $\mathrm{Na}_{2} \mathrm{HPO}_{4}$ \\
\hline $\mathrm{K}_{2} \mathrm{SO}_{4}$ & $\mathrm{Na}_{2} \mathrm{SO}_{4}, \mathrm{MgSO}_{4}, \mathrm{CuSO}_{4}$ \\
\hline $0.05 \mathrm{M}$ potassium saccharate & $\mathrm{Na}_{2} \mathrm{CO}_{3}$ \\
\hline $10 \%$ ethanol & $0.03 \mathrm{~m}$ quinine hydrochloride \\
\hline $0.05 \%$ tetrodotoxin & $0.03 \mathrm{M} \mathrm{HCl}, \mathrm{H}_{2} \mathrm{SO}_{4}$ \\
\hline $0.1 \%$ lidocaine hydrochloride & \\
\hline
\end{tabular}

an effect of diminishing negative component of action potentials, a number of salts with different combinations of cations and anions were tested. They are listed in Table 1 grouped into effective and ineffective salts. It revealed that potassium, rubidium and cesium ions were effective. On the other hand the other salts tested showed no effect on the action potentials, even if $2 \mathrm{M} \mathrm{NaCl}$ or $2 \mathrm{M}$ $\mathrm{CaCl}_{2}$ was applied for $10 \mathrm{~min}$. In addition to potassium salts, effective nonelectrolytes tested were ethanol $(10 \mathrm{~g}$ in $\mathrm{dl}$ solution), tetrodotoxin $(0.05 \mathrm{~g}$ in $\mathrm{dl}$ solution) and lidocaine hydrochloride $(0.1 \mathrm{~g}$ in $\mathrm{dl}$ solution). They induced the reduction of the negative components in less than $20 \mathrm{sec}$.

Reduction and recovery time of the negative components

Reduction time, which is expressed as the time needed for $50 \%$ decrease of amplitude of negative components after application of each solution to a papilla, was measured. The time for $0.1 \mathrm{M} \mathrm{KCl}$ in Ringer ranged from 6 to $26 \mathrm{sec}$ and its mean value was $10 \mathrm{sec}$. Recovery time needed for $50 \%$ recovery after return to Ringer following application of $0.1 \mathrm{M} \mathrm{KCl}$ for $15 \mathrm{sec}$ ranged from 13 to $50 \mathrm{sec}$ and the mean was $33 \mathrm{sec}$. Figure 6 shows relative reduction time and relative recovery time, each of which is expressed as the ratio to the corresponding times for $0.1 \mathrm{M} \mathrm{KCl}$ in Ringer solution respectively, of thirteen $0.1 \mathrm{M}$ electrolytes and three nonelectrolytes. The relative recovery time of divalent and trivalent potassium salts were significantly longer than that of monovalent ones $(p<0.05)$, though there was no significant difference among their reduction time. Among the monovalent salts, $\mathrm{CsCl}$ had a prominently long reduction and short recovery time. Although only the values of $\mathrm{KCl}$ are shown in the Fig. 6, the reduction and re- 


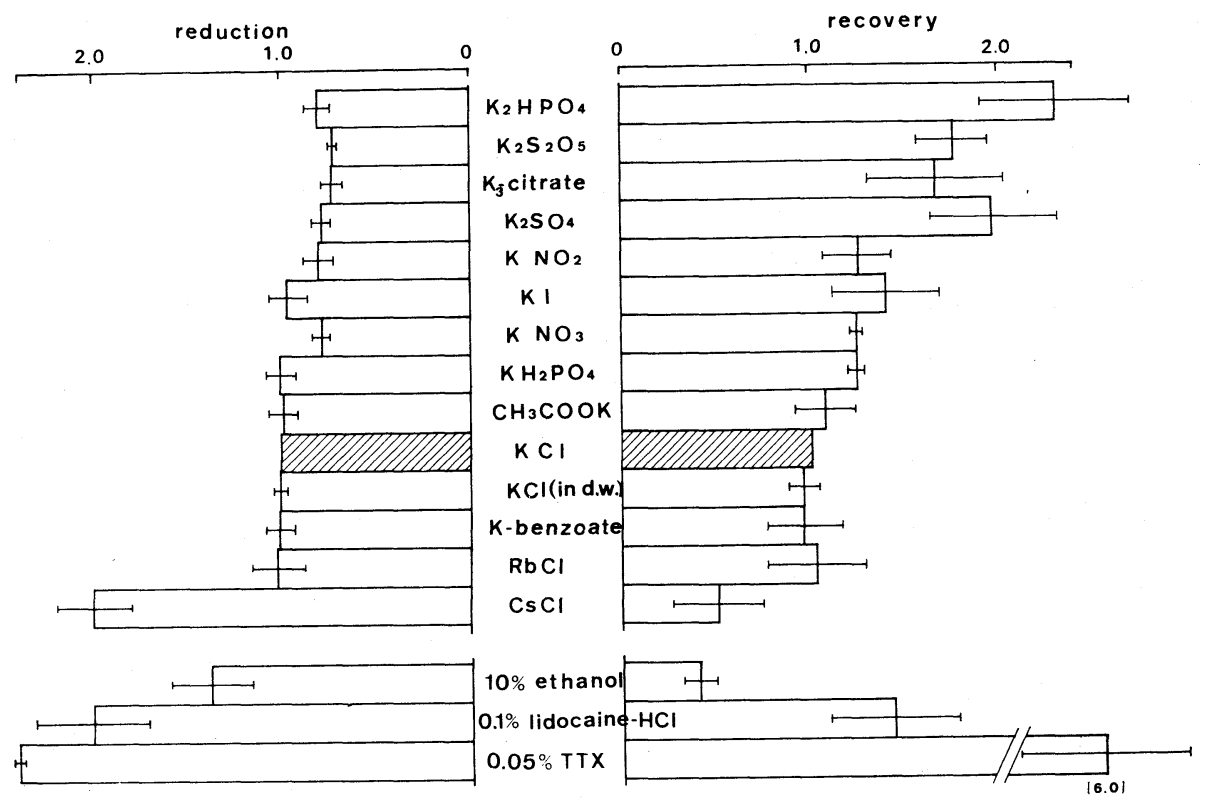

Fig. 6. Relative time required for decrease of negative components to half amplitude after application of $0.1 \mathrm{M}$ test solutions to the recorded papilla (left side) and relative time to recovery to half amplitude after return to Ringer solution (right side). The reduction and recovery times to half amplitude of $0.1 \mathrm{M} \mathrm{KCl}$ in Ringer solution were taken as 1 respectively and shown by cross-hatched columns. Thin horizontal bars indicate standard error. Both values of each chemical shown in this figure are only those of Ringer-solution except $\mathrm{KCl}$ in deionized water.

covery time values of each salt dissolved in deionized water were nearly equal to those in Ringer solution. The reduction time of three nonelectrolytes tested were about twice as long as that of potassium salts. Of the effective nonelectrolytes, tetrodotoxin needed more than six times the duration of $\mathrm{KCl}$ to recover to $50 \%$ amplitude, and 4 papillae of 11 tested did not recover within 20 min.

The recovery time from each application increased with the duration of the application time of test solution.

\section{Relation between reduction time and concentration}

Figure 7 represents the relation between the concentration and the relative reduction time as in Fig. 6 of 9 chemicals in Ringer. The logarithm of the relative reduction time of each chemical decreased approximately linearly with the logarithm of the concentration.

The reduction time of $5 \mathrm{~mm} \mathrm{KCl}$, which amounted to $6.9 \mathrm{~mm}$ together with the original $\mathrm{KCl}$ in Ringer solution and was the threshold concentration, was about $60 \mathrm{sec}$ and that of $10 \mathrm{~mm}$ potassium benzoate and potassium acetate was 30 to $40 \mathrm{sec}$. Potassium sulfate had shorter reduction time than the monovalent 


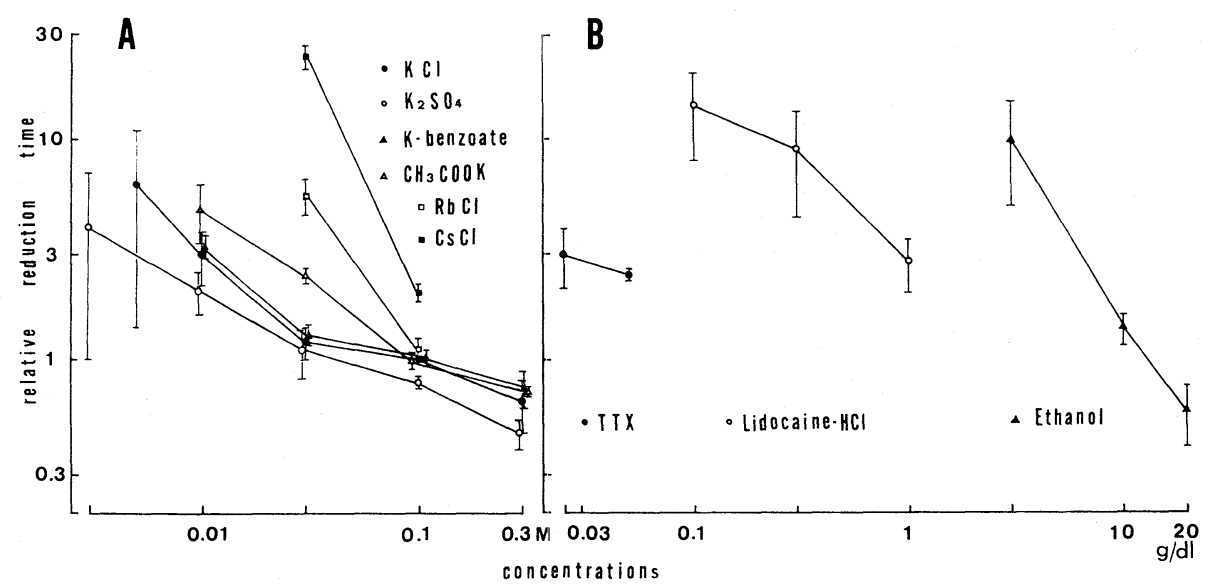

Fig. 7. Relative reduction time (ordinates) of negative components against various concentrations (abscissae) of 9 chemicals dissolved in Ringer solution. (A): electrolytes. (B): nonelectrolytes. The unit time was the half decay time of $0.1 \mathrm{M} \mathrm{KCl}$ as in the Fig. 6 .

salts at all the molar concentrations. The threshold concentration of $\mathrm{RbCl}$ and $\mathrm{CsCl}$ was $0.03 \mathrm{M}$. Threshold of tetrodotoxin, lidocaine hydrochloride and ethanol were $0.025,0.1$ and $3 \mathrm{~g}$ in dl solution respectively.

Change in excitability of papillary nerves during application of various chemicals

A single suctioned papilla was electrically stimulated and nerve action potentials were recorded from the glossopharyngeal nerve. The threshold current was measured when $0.1 \mathrm{M} \mathrm{KCl}, 0.1 \mathrm{M} \mathrm{LiCl}$ and $0.05 \mathrm{M} \mathrm{BaCl}_{2}$ were applied through the electrode. Figure 8 shows the time courses of relative thresholds for $60 \mathrm{sec}$ after onset of the test solutions, which were expressed as percent of the control threshold under Ringer solution. The relative threshold of $\mathrm{BaCl}_{2}$ decreased but that of $\mathrm{KCl}$ increased significantly within $10 \mathrm{sec}$. $\mathrm{LiCl}$ increased the threshold too, but more than $20 \mathrm{sec}$. The threshold changes caused by these chemicals increased with the elaspse of application time.

\section{DISCUSSION}

It is well-known that the excess of external potassium causes a shift of the membrane potential of the nerve fiber in the depolarizing direction and results in a increase of threshold or conduction block of the action potentials (HoDGKIN, 1947, 1951; Sato and FuKuda, 1953; Hashimura and Wright, 1958; Kuffler et al., 1966; DeVoe, 1974). In the present experiment, it was found that the conduction block of the papillary nerve induced by potassium ions caused the abolition of the negative components of nerve action potentials. Hereupon two mechanisms of conduction block of nerve fibers can be considered. One is that applica- 


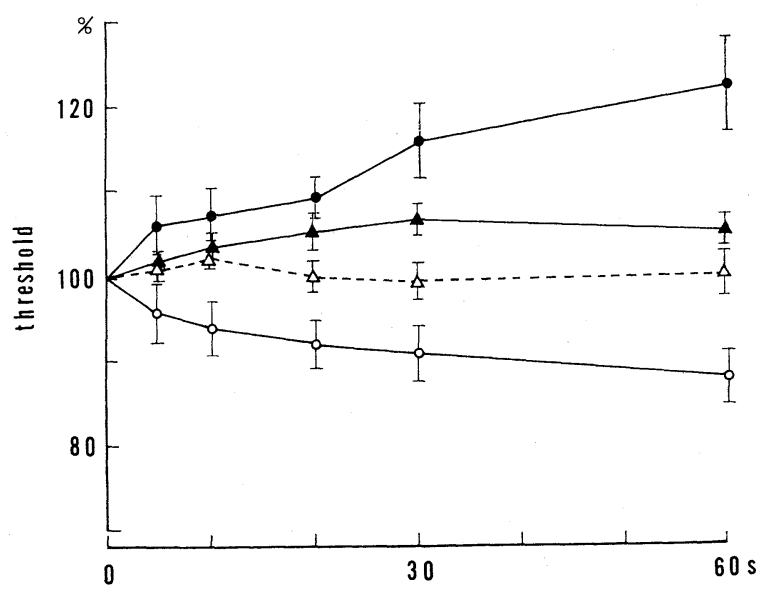

Fig. 8. Time courses of relative current threshold of papillary nerve. Ordinate: threshold current expressed as percentage during application of three test chemicals and Ringer solution as control. Threshold for Ringer solution just before application of each test solution was taken as $100 \%$. $\quad 0.1 \mathrm{M} \mathrm{KCl} ; \Delta, 0.1 \mathrm{M} \mathrm{LiCl} ; 0,0.05 \mathrm{M} \mathrm{BaCl}_{2} ; \triangle$, Ringer solution. Each test electrolyte was dissolved in deionized water. Vertical bars indicate standard error. Abscissa: time after the onset of test solution.

tion of potassium ions induced depolarization of taste cells, which then might subsequently cause depolarization of primary afferent fibers and reduction of the excitability through the synapses between taste cells and gustatory fibers. The other is that applied potassium ions could penetrate the tongue epithelium and act directly on papillary nerve fibers or the synapses between taste cells and nerve to reduce the nerve excitability. The latter may be more likely on the following accounts: First, the conduction block induced by potassium salts still occurred, even if the preparation had already undergone fatigue and could hardly respond to any chemical stimulus applied to the papilla. Second, tetrodotoxin, which does not affect the gustatory cells (OzeKi and Noma, 1972; Akaike and SATo, 1975 ) induces the abolition of the negative components of action potentials in the same manner as potassium salts. Further, it has been suggested by TAGLIETTI and CASELla (1971) that chemicals can penetrate into tongue and change the excitability of gustatory nerves, though a much longer time was needed in their experiment.

Effective nonelectrolytes tested were also thought to penetrate the tongue mucous membrane and to diffuse to the axon surface, although the mechanism of conduction block must be different from potassium ions. In the study on mammals ethanol can penetrate the rat tongue epithelium, although more than 60 min was needed (MistretTA, 1971). Lidocaine hydrochloride can also diffuse through mucous membrane of mammals to nerve fibers beneath it and is commonly used for surface anesthesia. 
If potassium ions can rapidly penetrate inside the frog tongue, two possible routes are considered through which they diffuse. One is the gap between sensory cells and accessory cells at the papilla disc, though they tightly contact each other with gap junctions (GraziadeI and DeHAN, 1971). The other is between epithelial cells of the side wall of a papilla. It is likely that the ions diffuse more rapidly to the papillary nerve through the sensory disc than through the side epithelium of the papilla, since the distance between the mucous membrane surface and the nerve fibers beneath it must be shorter at the disc than at the side of the papilla. In fact, when the side of papilla was suctioned excepting the disc, the time required to reduce the negative components of action potentials recorded from the papilla to half amplitude was several times as long as when the papilla was suctioned including its disc.

KUSANO (1958) reported that potassium ions depressed gustatory responses in the frog after the tongue was soaked in potassium-rich solution. This could be interpreted in terms of inhibition induced by penetrated potassium ions on the afferent fibers. The nerve discharges in the frog glossopharyngeal nerve elicited by application of $\mathrm{NaCl}$ to the tongue persist for a long period. On the other hand, the response to $\mathrm{KCl}$ possesses a remarkable initial part but a much smaller tonic response compared with the rat chorda tympani in which the gustatory response to either $\mathrm{NaCl}$ or $\mathrm{KCl}$ is maintained as long as the stimulus is applied. The potassium ion-induced inhibition could be one of the reasons of such a depression of tonic response in the frog.

The electrophysiological approach of the present experiment revealed that the potassium, cesium, rubidium ion and some others, which change nerve excitability, can rapidly penetrate the frog tongue. They must contribute or modify the gustatory information with exception of transient response occurring immediately after the stimulus onset when those substances does not reach and affect the nerve terminal yet. However, it may be suggested that the other ions or chemical substances, which seemed to show no effect on nerve excitabilities, can also penetrate the mucous membrane rapidly.

The author wishes to express his thanks to Professor M. Ichioka for instruction and encouragement, to Dr. T. Sato for valuable discussion and also to Dr. N. Akaike (Kumamoto Univ.) for valuable suggestion. Thanks are also due to Drs. D. Price (National Institutes of Health, U.S.A.) and A. Browe (Indiana Univ., U.S.A.) for their critical reading of the manuscript.

\section{REFERENCES}

Akaike, N. and Sato, M. (1975) Effect of local anesthetics on taste cell responses. Jap. J. Physiol., 25: 585-597.

Beidler, L. M. (1961) Taste receptor stimulation. Prog. Biophys. Biophys. Chem., 12: 107-151. BEIDLER, L. M. (1965) Comparison of gustatory receptors, olfactory receptors, and free nerve endings. Cold Spring Harbor Symp. Quant. Biol., 30: 191-200.

BINLEY, F. J., JR. (1974) Excitation and conduction in nerve fibers. In: Medical Physiology, 
ed. by Mountcastle, C. V. Mosby Co., Saint Louis, Vol. 1, p. 39.

DeVoe, R. D. (1974) Principles of cell homeostasis. In: Medical Physiology, ed. by MountCAStle, C. V. Mosby Co., Saint Louis, Vol. 1, pp. 3-33.

Graziadei, P. P. C. and DeHan, R. S. (1971) The ultrastructure of frog's taste organs. Acta Anat., 80: 563-603.

HaShimuRA, M. and WRIGHT, E. B. (1958) Effect of ionic environment on excitability and electrical properties of frog single nerve fiber. J. Neurophysiol., 21 : 24-44.

Hayashi, H. (1976) Penetration of potassium ions and some others into the frog tongue papilla and its effect on taste response. 10th Jap. Symp. Taste and Smell, pp. 77-80.

Hellekant, G. (1965) The effect of ethyl alcohol on non-gustatory receptors of the tongue of the cat. Acta Physiol. Scand., 65: 243-250.

Hodgkin, A. L. (1947) The effect of potassium on the surface membrane on an isolated axon. J. Physiol., 106: 319-340.

Hodgkin, A. L. (1951) The ionic basis of electrical activity in nerve and muscle. Biol. Rev., 26: 339-409.

Kuffler, S. M., Nicholls, J. G., and Orkand, R. K. (1966) Physiological properties of glial cells in the central nervous system of amphibia. J. Neurophysiol., 29: 768-787.

KusANO, K. (1958) The influence of cation on the activity of gustatory receptors, I. Effect of KCl. Kumamoto Med. J., 11: 174-183.

Miller, I. J., JR. (1971) Peripheral interaction among single papilla input to gustatory nerve fibers. J. Gen. Physiol., 57: 1-25.

Mistretta, M. C. (1971) Permeability of tongue epithelium and its relation to taste. Am. J. Physiol., 220: 1162-1167.

OzeKI, M. and Noma, A. (1972) The actions of tetrodotoxin, procaine and acetylcholine on gustatory receptors in frog and rat. Jap. J. Physiol., 22: 467-475.

SAto, M. and Fukuda, T. (1953) Measurements of threshold, resting potential and action current of myelinated nerve fibers in relation to the outside potassium concentration. Jap. J. Physiol., 3: 297-305.

Shanes, A. M., Freygang, W. H., Grundfest, H., and Amatinek, E. (1959) Anesthetics and calcium action in the voltage clamped squid giant axon. J. Gen. Physiol., 42: 793-802.

Taglietti, V., Casella, C., and Ferrari, E. (1969) Interactions between taste receptors in the frog tongue. Pflüger Arch., 312: 139-148.

TAglietti, S. M. and CASElla, C. (1971) The recovery cycle of gustatory fibres during chemical stimulation of the tongue. Arch. Sci. Biol., 55: 155-164. 